\title{
Metformin exposure is associated with improved progression-free survival in diabetic patients after resection for early-stage non-small cell lung cancer
}

\author{
Robert A. Medairos, BS, ${ }^{\mathrm{a}}$ James Clark, MS, ${ }^{\mathrm{a}}$ Simon Holoubek, DO, ${ }^{\mathrm{a}}$ John C. Kubasiak, MD, \\ Ravi Pithadia, MD ${ }^{\mathrm{c}}$ Fatima Hamid, MD,${ }^{\mathrm{d}}$ Gary W. Chmielewski, MD, ${ }^{\mathrm{a}}$ William H. Warren, MD, ${ }^{\mathrm{a}}$ \\ Sanjib Basu, PhD, ${ }^{\mathrm{e}}$ Jeffrey A. Borgia, PhD, ${ }^{\mathrm{c}, \mathrm{d}}$ Michael J. Liptay, MD, ${ }^{\mathrm{a}}$ and Christopher W. Seder, $\mathrm{MD}^{\mathrm{a}}$
}

\begin{abstract}
Objective: There are little clinical data assessing the antineoplastic effect of metformin in patients with non-small cell lung cancer. We hypothesized that in diabetic patients undergoing pulmonary resection for early-stage non-small cell lung cancer, metformin exposure is associated with improved survival.

Methods: An institutional database was used to identify patients with stage I or II non-small cell lung cancer who underwent pulmonary resection between 2004 and 2013. Patients were divided into 3 cohorts: type II diabetic patients with metformin exposure (cohort $\mathrm{A}, \mathrm{n}=81$ ), type II diabetic patients without metformin exposure (cohort $\mathrm{B}, \mathrm{n}=57$ ), and nondiabetic individuals (cohort $\mathrm{C}, \mathrm{n}=77$ ). Univariate, multivariate, and propensity-matched analyses were performed to assess progression-free and overall survivals between groups.
\end{abstract}

Results: A total of 215 patients with stage I and II non-small cell lung cancer treated with surgical resection were identified for analysis with a median follow-up of 19.5 months. Patients in cohort A had lower T- and N-stage tumors than those in cohorts B or C. However, on multivariate analysis adjusting for age, gender, and $\mathrm{T}$ and $\mathrm{N}$ stage, progression-free survival was greater for cohort $\mathrm{A}$ than cohort B (hazard ratio [HR], 0.410; 95\% confidence interval, 0.199-0.874; $P=.022)$ or cohort C (HR, 0.415; 95\% confidence interval, 0.201-0.887; $P=.017)$. Likewise, when propensity-matched analyses were performed, cohort A demonstrated a trend toward improved progression-free survival compared with cohort B $(P=.057 ; \mathrm{HR}, 0.44 ; \mathrm{c}$-statistic $=0.832)$ and improved progression-free survival compared with cohort $\mathrm{C}(P=.02 ; \mathrm{HR}, 0.41 ; \mathrm{c}$-statistic $=0.843)$. No differences were observed in overall survival.

Conclusions: Metformin exposure in diabetic patients with early-stage non-small cell lung cancer may be associated with improved progression-free survival, but no effect was seen on overall survival. Further studies are warranted to evaluate if there is a therapeutic role for metformin in the treatment of non-small cell lung cancer. (J Thorac Cardiovasc Surg 2016;152:55-61)

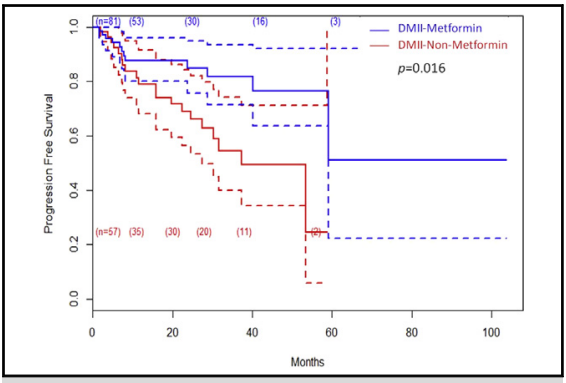

PFS: metformin-exposed versus nonmetforminexposed patients.

Central Message

Metformin exposure in type 2 diabetic patients with NSCLC is associated with improved PFS

Perspective

Metformin exposure in patients who underwent pulmonary resection for early-stage NSCLC may be associated with improved PFS. Further prospective studies assessing metformin as an adjuvant agent in lung cancer are needed to determine whether there is a role for metformin in the treatment of early-stage lung cancer.

See Editorial Commentary page 62
Lung cancer is the leading cause of cancer death, with more than 220,000 patients being diagnosed in the United States in 2014, resulting in approximately 160,000 deaths during this period. ${ }^{1}$ Unfortunately, the 5 -year survival for patients with lung cancer remains

\footnotetext{
From the Departments of ${ }^{\mathrm{a} C a r d i o v a s c u l a r}$ and Thoracic Surgery, ${ }^{\mathrm{b}}$ General Surgery, ${ }^{\mathrm{c}}$ Biochemistry, ${ }^{\mathrm{d}}$ Pathology, and ${ }^{\mathrm{e}}$ Preventative Medicine, Rush University Medical Center, Chicago, Ill.

Read at the 95th Annual Meeting of The American Association for Thoracic Surgery, Seattle, Washington, April 25-29, 2015.

Received for publication April 26, 2015; revisions received Feb 17, 2016; accepted for publication March 13, 2016; available ahead of print May 6, 2016.
}

poor at approximately $15 \%$, because most patients are diagnosed with late-stage disease when curative therapy is no longer available. ${ }^{2}$ Therefore, novel therapies aimed at improving survival in lung cancer are of utmost importance.

\footnotetext{
Address for reprints: Christopher W. Seder, MD, Rush University Medical Center, 1725 W. Harrison St, Suite 774, Chicago, IL 60612 (E-mail: Christopher_W_Seder@rush.edu). 0022-5223/\$36.00

Copyright (C) 2016 by The American Association for Thoracic Surgery http://dx.doi.org/10.1016/j.jtcvs.2016.03.094
} 


\section{Abbreviations and Acronyms \\ AMPK $=$ AMP-activated protein kinase \\ BMI = body mass index \\ ECOG = Eastern Cooperative Oncology Group \\ HR = hazard ratio \\ IGF-1 = insulin-like growth factor 1 \\ NSCLC $=$ non-small cell lung cancer \\ OS = overall survival \\ PFS = progression-free survival}

Scanning this QR code will take you to supplemental tables for this article.

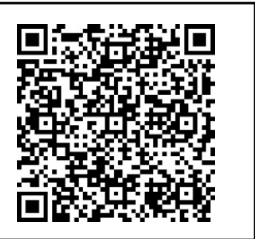

Emerging evidence suggests that metformin, a biguanide commonly used to treat type 2 diabetes, may serve as an adjuvant agent to reduce cancer risk and improve survival in certain cancers, including breast and colorectal. ${ }^{3,4}$ In addition, in vitro and in vivo studies have suggested metformin has an antineoplastic effect. ${ }^{5,6}$ Studies of human non-small cell lung cancer (NSCLC) cells in a murine model have demonstrated that metformin inhibits tumor cell proliferation via activation of the ataxia telangiectasiamutated AMP-activated protein kinase (AMPK) pathway, inducing p53- and p21-mediated G1 cycle arrest and apoptosis. ${ }^{7}$ Recent studies examining the association between metformin use and survival among diabetic patients with advanced-stage NSCLC have demonstrated conflicting results. ${ }^{8-11}$ Furthermore, the effect of metformin on progression-free survival (PFS) and overall survival (OS) in patients with early-stage NSCLC has yet to be determined. We hypothesized that preoperative metformin exposure is associated with improved survival in diabetic patients with early-stage lung cancer who underwent pulmonary resection.

\section{PATIENTS AND METHODS}

After Institutional Review Board approval, all patients who underwent pulmonary resection for stage I or II NSCLC between 2004 and 2013 at Rush University Medical Center were identified. Inclusion criteria were age more than 18 years, type 2 diabetes, and histologically confirmed stage I or II NSCLC. A control group of nondiabetic patients was identified by querying our departmental database for all patients who underwent pulmonary resection for stage I or II NSCLC during the study period. Exclusion criteria included only patients who did not consent to clinical data collection for research purposes. All stage classifications are reported according to the American Joint Committee on Cancer seventh edition criteria and confirmed by pathological evaluation. ${ }^{12,13}$ The following demographic data were abstracted from each patient record: age, sex, gender, race, calculated body mass index (BMI), preoperative Eastern Cooperative Oncology Group (ECOG) score, and tobacco smoking history.
Additional data extracted from the records included pathologic TNM stage, tumor histology, adjuvant chemotherapy, preoperative renal function and fasting serum glucose, diabetic medication regimen, metformin dosage, surgical procedure, prior malignancy of any type, and comorbidities. Patients were classified as having metformin exposure if they had documented use of metformin within 6 months before the surgical resection, in accordance with previously published studies. ${ }^{6,14}$ For every patient, charts were reviewed through the most recent followup date for metformin exposure.

Patients were divided into 3 groups for comparison: cohort A (type 2 diabetic patients with metformin exposure), cohort B (type 2 diabetic patients without metformin exposure), and cohort $\mathrm{C}$ (nondiabetic patients). Patient demographics, treatment strategies, and survival were compared between groups. All patients were followed with a history, physical, and a noncontrast chest computed tomography scan every 6 months for the first 2 years and then yearly for life. OS was calculated as the time from date of surgery to death or last documented follow-up. PFS was calculated from the date of surgery to the date of first recurrence, defined as the last date of negative radiographic imaging and clinical examination. If there was no recurrence, and the patient died, the PFS was based on the date of death. PFS and OS curves were estimated by Kaplan-Meier method and compared across groups by log-rank tests. Hazard ratios (HRs) and association of PFS or OS with multiple covariates were assessed using the Cox proportional hazards model. To reduce confounding effects, adjusted Kaplan-Meier estimates and log-rank tests based on inverse propensity score of treatment weighting were calculated, as previously described. ${ }^{15-17}$

\section{RESULTS}

A total of 215 patients with stage I or II NSCLC who underwent pulmonary resection were examined. Median follow-up was 19.5 months. Cohort A $(\mathrm{n}=81)$ consisted of type II diabetic patients exposed to metformin, cohort B $(\mathrm{n}=57)$ consisted of type II diabetic patients without metformin exposure, and cohort $\mathrm{C}(\mathrm{n}=77)$ consisted of nondiabetic individuals without metformin exposure. One patient in cohort B was placed on metformin 2 years after surgical resection. There were no differences in age, gender, BMI, race, comorbidities, preoperative ECOG score, pathologic stage, procedure, or adjuvant chemotherapy use observed between cohorts. Cohort A had a lower T stage than cohort $\mathrm{C}$, and there was a trend toward fewer patients with $\mathrm{N} 1$ cancer in cohort A than cohorts B or C. In addition, cohort $\mathrm{C}$ had more current smokers and lower creatinine and serum glucose levels than cohorts A or B (Tables 1 and 2).

During the study period, 21 patients died, $47.6 \%(10 / 21)$ with evidence of recurrence and 52.4\% (11/21) without recurrence (Figure 1, A). By examining patients with recurrence $(\mathrm{n}=46), 54.3 \%(25 / 46)$ had local recurrence and $45.7 \%(21 / 46)$ had recurrence in distant locations (Figure 1,B). There were 37 of 106 diabetic patients (cohorts $\mathrm{A}$ and $\mathrm{B}$ ) and 32 of 52 nondiabetic patients (cohort C) who were lost to follow-up (defined as alive without recurrence with $>1$ year between the date of last followup and data collection).

Among type II diabetic patients, PFS was greater for patients in group A (metformin exposure, median PFS not reached) than in group B (nonmetformin, median $=37.4$ months), (HR, 0.406; 95\% confidence interval [CI], 0.194-0.848; 
TABLE 1. Patient demographics*

\begin{tabular}{|c|c|c|c|c|}
\hline & $\begin{array}{c}\text { Cohort A } \\
\text { DM II metformin } \\
(\mathbf{n}=\mathbf{8 1}) \\
\end{array}$ & $\begin{array}{c}\text { Cohort B } \\
\text { DM II nonmetformin } \\
(\mathbf{n}=\mathbf{5 7}) \\
\end{array}$ & $\begin{array}{c}\text { Cohort } \mathbf{C} \\
\text { Nonmetformin } \\
(\mathbf{n}=\mathbf{7 7}) \\
\end{array}$ & $P$ value \\
\hline Age $(y \pm S D)$ & $69.0 \pm 8.9$ & $70.4 \pm 9.67$ & $68.0 \pm 10.2$ & .396 \\
\hline Gender (male) & $42(51.9)$ & $32(56.1)$ & $38(49.4)$ & .738 \\
\hline \multicolumn{5}{|l|}{ Smoking history } \\
\hline Pack-years $( \pm \mathrm{SD})$ & $34.7 \pm 32.2$ & $35.9 \pm 34.4$ & $38.2 \pm 33$ & .809 \\
\hline Current smoker & $14(17.3)$ & $14(24.6)$ & $28(36.4)$ & .023 \\
\hline Never smoker & $15(18.5)$ & $11(19.3)$ & $11(14.3)$ & .693 \\
\hline $\mathrm{BMI}\left(\mathrm{kg} / \mathrm{m}^{2} \pm \mathrm{SD}\right)$ & $31.4 \pm 7.2$ & $29.4 \pm 6.2$ & $26.3 \pm 4.5$ & .085 \\
\hline Preoperative FSG $(\mathrm{mg} / \mathrm{dL} \pm \mathrm{SD})$ & $132.5 \pm 48.9$ & $142.34 \pm 63.9$ & $100 \pm 18.5$ & $<.001$ \\
\hline Preoperative creatinine & $1.0 \pm 1.4$ & $1.7 \pm 1.4$ & $1.0 \pm 0.3$ & $<.001$ \\
\hline Preoperative ECOG score & & & & .528 \\
\hline 0 & $19(23.5)$ & $15(26.3)$ & $27(35.1)$ & \\
\hline 1 & $42(51.9)$ & $31(54.4)$ & $37(48.1)$ & \\
\hline 2 & $18(22.2)$ & $8(14)$ & $11(14.3)$ & \\
\hline 3 & $2(2.5)$ & $3(5.3)$ & $2(2.6)$ & \\
\hline Race & & & & .950 \\
\hline Caucasian, non-Hispanic & $57(70.4)$ & $40(70.2)$ & $61(79.2)$ & \\
\hline African American/Black & $15(18.5)$ & $12(21.1)$ & $11(14.3)$ & \\
\hline Hispanic & $2(2.5)$ & $1(1.7)$ & $1(1.3)$ & \\
\hline Asian & $3(3.7)$ & $1(1.7)$ & $2(2.6)$ & \\
\hline Other & $4(4.9)$ & $3(5.3)$ & $1(1.3)$ & \\
\hline Diabetic medication & & & & $<.001$ \\
\hline Insulin & $10(12.3)$ & $23(40.4)$ & 0 & \\
\hline Nonmetformin/noninsulin & 0 & $18(31.6)$ & 0 & \\
\hline Diet controlled & 0 & $16(28.1)$ & 0 & \\
\hline \multicolumn{5}{|l|}{ Comorbidities } \\
\hline HTN & $61(75.3)$ & $44(77.2)$ & $49(63.6)$ & .147 \\
\hline Hyperlipidemia & $41(50.6)$ & $28(49.1)$ & $25(32.9)$ & .054 \\
\hline Dialysis & 0 & $1(1.7)$ & 0 & .999 \\
\hline Prior malignancy of any type & $32(39.5)$ & $16(28.1)$ & $26(33.8)$ & .379 \\
\hline COPD & $21(25.9)$ & $14(24.6)$ & $21(27.3)$ & .939 \\
\hline
\end{tabular}

Boldface indicates $P<.05 . D M$, Diabetes mellitus; $S D$, standard deviation; $B M I$, body mass index; $F S G$, fasting serum glucose; ECOG, Eastern Cooperative Oncology Group; $H T N$, hypertension; $C O P D$, chronic obstructive pulmonary disease. *All data presented as $\mathrm{n}(\%)$ unless otherwise specified.

$P=.016$ ) (Figure 2, A). On multivariate analysis, after adjusting for age, gender, and T and $\mathrm{N}$ stage, metformin use in type II diabetic patients was significantly associated with PFS (HR, $0.410 ; 95 \%$ CI, 0.199-0.874; $P=.022$ ). In an inverse propensity-weighted analysis, with propensity score based on age, gender, histology, and $\mathrm{T}$ and $\mathrm{N}$ stage (group $\mathrm{A}, \mathrm{n}=81$; group $\mathrm{B}, \mathrm{n}=57$ ), the difference in PFS between the metformin and nonmetformin groups remained significant $(P=.043 ; \mathrm{HR}$, 0.46 ; c-statistic $=0.658)$. With a propensity score based on age, gender, histology, $\mathrm{T}$ and $\mathrm{N}$ stage, serum creatinine, and fasting serum glucose (group $\mathrm{A}, \mathrm{n}=71$; group $\mathrm{B}, \mathrm{n}=49$ ), the difference in PFS between the metformin and nonmetformin groups trended toward significance $(P=.057$; HR, 0.44 ; c-statistic $=0.832$; standardized differences in Table E1).

Similar results were observed when comparing PFS between group A (metformin exposure, median PFS not reached) and group $\mathrm{C}$ (nondiabetic, median 42.3 months) (HR, 0.446; 95\% CI, 0.223-0.891; $P=.022$ ) (Figure 2, $B)$. On multivariate analysis, after adjusting for age, gender, and $\mathrm{T}$ and $\mathrm{N}$ stage, metformin use in diabetic patients was significantly associated with PFS compared with PFS in nondiabetic patients (HR, 0.415; 95\% CI, 0.201-0.887; $P=.017)$. In an inverse propensity-weighted analysis based on age, gender, histology, and $\mathrm{T}$ and $\mathrm{N}$ stage (group $\mathrm{A}$, $\mathrm{n}=81$; group $\mathrm{C}, \mathrm{n}=77$ ), the difference in PFS between groups $\mathrm{A}$ and $\mathrm{C}$ remained significant $(P=.007$; HR, 0.37 ; c-statistic $=0.744)$. With a propensity score based on age, gender, histology, T and N stage, BMI, ECOG score, and chronic obstructive pulmonary disease (group A, $\mathrm{n}=71$; group $\mathrm{C}, \mathrm{n}=49$ ), the difference in PFS between the metformin and nondiabetic groups remained significant $(P=.02 ; \mathrm{HR}, 0.41 ; \mathrm{c}$-statistic $=0.843)$ (standardized differences in Table E2).

Among patients exposed to metformin (cohort A), most received $500 \mathrm{mg}(\mathrm{n}=43)$ or $1000 \mathrm{mg}$ daily $(\mathrm{n}=34)$, whereas 1 patient received $750 \mathrm{mg}$ and 3 patients received $850 \mathrm{mg}$ daily. When divided into "low-dose" (500$750 \mathrm{mg} / \mathrm{d})$ or "high-dose" (850-1000 mg/d) metformin exposure, the association between dose and PFS was not significant $(P=.703)$ (Figure 3$)$. OS did not differ 
TABLE 2. Staging, treatment, and histologic characteristics*

\begin{tabular}{|c|c|c|c|c|}
\hline & $\begin{array}{c}\text { Cohort A } \\
\text { DM II metformin } \\
(\mathbf{n}=\mathbf{8 1}) \\
\end{array}$ & $\begin{array}{c}\text { Cohort B } \\
\text { DM II nonmetformin } \\
(\mathbf{n}=\mathbf{5 7})\end{array}$ & $\begin{array}{c}\text { Cohort C } \\
\text { Non-DM } \\
(\mathbf{n}=77) \\
\end{array}$ & $P$ value \\
\hline Pathologic stage & & & & .222 \\
\hline IA & $52(64.2)$ & $30(52.6)$ & $41(53.2)$ & \\
\hline IB & $17(21.0)$ & $12(21.1)$ & $25(32.5)$ & \\
\hline IIA & $6(7.4)$ & $8(14.0)$ & $8(10.4)$ & \\
\hline IIB & $6(7.4)$ & $7(12.3)$ & $3(3.9)$ & \\
\hline T-stage & & & & .028 \\
\hline $\mathrm{T} 1 \mathrm{a}$ & $40(49.4)$ & $24(42.1)$ & $27(35.1)$ & \\
\hline $\mathrm{T} 1 \mathrm{~b}$ & $14(17.3)$ & $10(17.5)$ & $16(20.8)$ & \\
\hline $\mathrm{T} 2 \mathrm{a}$ & $16(19.7)$ & $13(22.8)$ & $31(40.3)$ & \\
\hline $\mathrm{T} 2 \mathrm{~b}$ & $6(7.4)$ & $4(7.0)$ & $3(3.9)$ & \\
\hline $\mathrm{T} 3$ & $5(6.2)$ & $6(10.5)$ & 0 & \\
\hline $\mathrm{N}$-stage & & & & .062 \\
\hline No & $78(96.3)$ & $50(87.7)$ & $66(85.7)$ & \\
\hline N1 & $3(3.7)$ & $7(12.3)$ & $11(14.3)$ & \\
\hline Procedure & & & & .440 \\
\hline Lobectomy & $48(59.3)$ & $43(75.4)$ & $50(64.9)$ & \\
\hline Wedge resection & $24(29.6)$ & $10(17.5)$ & $21(27.2)$ & \\
\hline Segmentectomy & $2(2.5)$ & $1(1.7)$ & $3(3.9)$ & \\
\hline Pneumectomy & $5(6.2)$ & $1(1.7)$ & $3(3.9)$ & \\
\hline Bilobectomy & $2(2.5)$ & $2(3.5)$ & 0 & \\
\hline \multicolumn{5}{|l|}{ Chemotherapy } \\
\hline Adjuvant & $6(7.4)$ & $8(14.0)$ & $5(6.5)$ & .267 \\
\hline Platinum based & $5(6.2)$ & $5(8.8)$ & $3(4.9)$ & .503 \\
\hline Histology & & & & .002 \\
\hline Adenocarcinoma & $44(54.3)$ & $29(50.9)$ & $56(72.7)$ & \\
\hline Squamous cell carcinoma & $20(24.7)$ & $23(40.3)$ & $16(20.8)$ & \\
\hline Neuroendocrine & $12(14.8)$ & $5(8.8)$ & 0 & \\
\hline Carcinoma, NOS & $5(6.2)$ & $0(0.0)$ & $5(6.5)$ & \\
\hline
\end{tabular}

Boldface indicates $P<.05$. DM, Diabetes mellitus; NOS, not otherwise specified. *All data presented as n $(\%)$.

significantly between group A and group B (HR, 0.778; 95\% CI, 0.225-2.691; $P=.69$ ) (Figure $4, A$ ) or group A and group $\mathrm{C}(\mathrm{HR}, 0.47 ; 95 \% \mathrm{CI}, 0.163-1.362 ; P=.16)$ (Figure 4, B). The point estimates of the HR for OS suggest that there may be a signal here that is worth pursuing. A post hoc power calculation suggests that a sample size of 285 patients would be required in each group to have $80 \%$ power in detecting an HR of 0.47 for an OS with a $P=.05$.

\section{DISCUSSION}

Studies have reported a survival benefit in patients with metformin-treated type 2 diabetes and advanced-stage NSCLC..$^{8-10}$ The current study suggests an association between metformin exposure and improved PFS in diabetic patients with early-stage lung cancer treated with pulmonary resection. Although an OS difference was not proven, our results suggest a potential signal that might be better demonstrated with a larger sample size than we had in our study. These data contribute to a growing body of literature supporting the antineoplastic effect of metformin.

Although controversial, emerging evidence supports the use of metformin as an adjuvant agent in cancer therapy. ${ }^{18}$
A recent meta-analysis associated the use of metformin in type 2 diabetic patients with a $31 \%$ reduction in lifetime cancer risk and a $35 \%$ reduction in the risk of cancer mortality. ${ }^{18}$ Observational studies have suggested that metformin use in diabetic patients plays a protective role in breast and colorectal cancer, reducing incidence and mortality. 3,4,11,18-20 However, other reports have found no association between duration or dose of metformin use and cancer risk. ${ }^{21,22} \mathrm{~A}$ recent study failed to demonstrate a survival benefit from metformin use among type 2 diabetic patients with NSCLC treated with definitive chemoradiation. ${ }^{23}$ However, the small sample size, short duration of follow-up, and increased BMI, age, and associated hypertension in the metformin group may have prevented the detection of any survival benefit. ${ }^{23}$

Metformin primarily reduces circulating glucose levels in patients through AMPK activation mediated by liver kinase B1, a tumor suppressor protein that responds during metabolic stress. ${ }^{24}$ Proposed anticarcinogenic effects of metformin occur through the liver kinase B1/AMPK pathway by inhibition of the mammalian target of rapamycin pathway, causing inhibition of protein synthesis, cell 


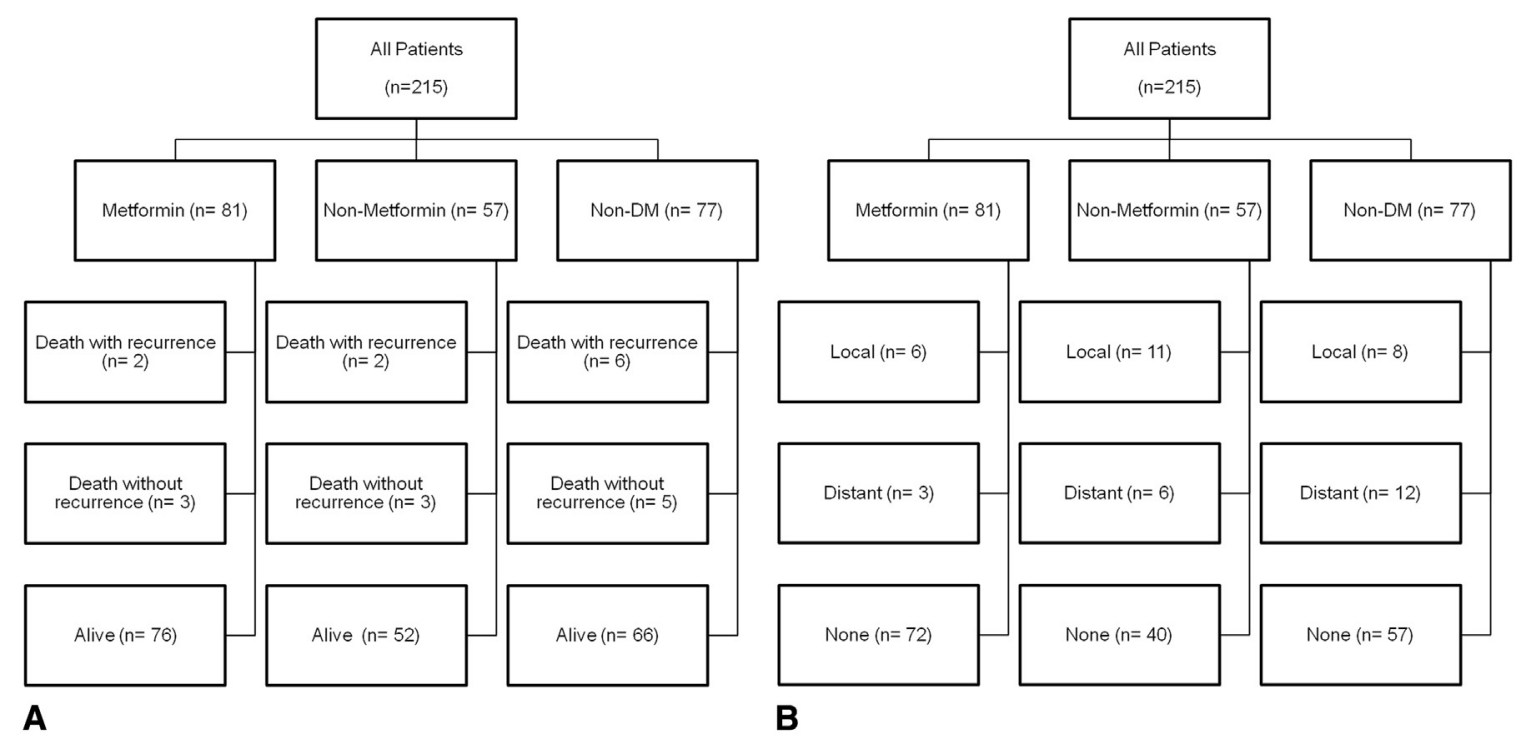

FIGURE 1. Death with and without recurrence (A) and local versus distant recurrence (B). DM, Diabetes mellitus.

cycle arrest, and apoptosis. ${ }^{25}$ Although a recent study has suggested that the activation of AMPK may fuel cell growth,${ }^{26}$ metformin also can inhibit the mammalian target of rapamycin pathway via the rag GTPase-dependent pathway, an AMPK-independent mechanism. ${ }^{27}$ Because elevated insulin-like growth factor 1 (IGF-1) can be protumorigenic, studies have explored the utility of metformin in reducing IGF-1-mediated tumorigenesis, demonstrating that metformin inhibited tobacco carcinogen-induced lung tumorigenesis in nondiabetic mice via decreased IGF-I levels independent of AMPK pathways. ${ }^{28}$ A significant decrease in tumorigenesis via rag GTPase-dependent pathway and modulating receptor-tyrosine kinase activity, independent of the IGF-1 level reduction, has been demonstrated in mice treated with metformin. ${ }^{28}$ Furthermore, clinically achievable metformin doses have been reported to enhance the response of NSCLC cells to ionizing radiation via the AMPK-dependent pathway. ${ }^{29}$

Although promising evidence from population-based, in vitro, and animal models exist, few studies have assessed the direct influence of metformin on survival. ${ }^{8-10,30}$ Mazzone and colleagues ${ }^{30}$ reported a reduced risk of developing lung cancer in diabetic patients receiving metformin; however, metformin therapy was associated with more aggressive histologic subtypes and metastatic disease. It has been suggested that lung cancers that develop in the presence of metformin may bypass key energy regulatory mechanisms, presenting with more aggressive phenotypes. Another retrospective study reported reduced lung cancer mortality in patients with type 2 diabetes treated with

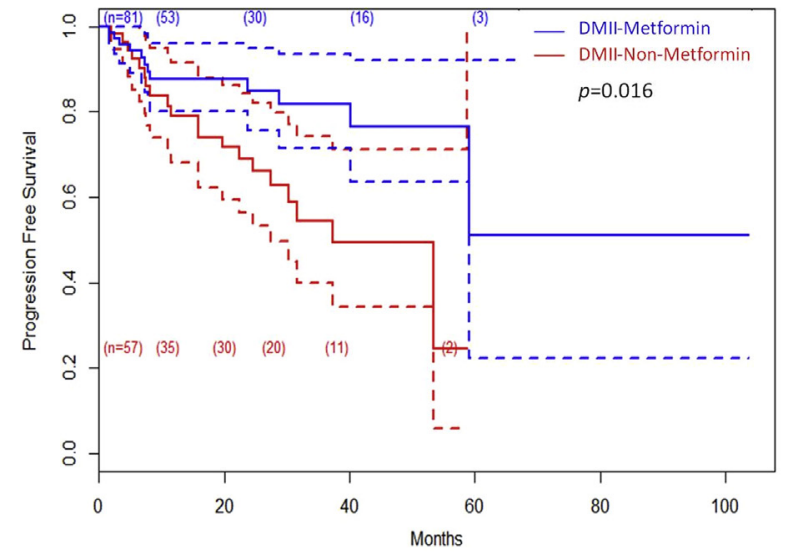

A

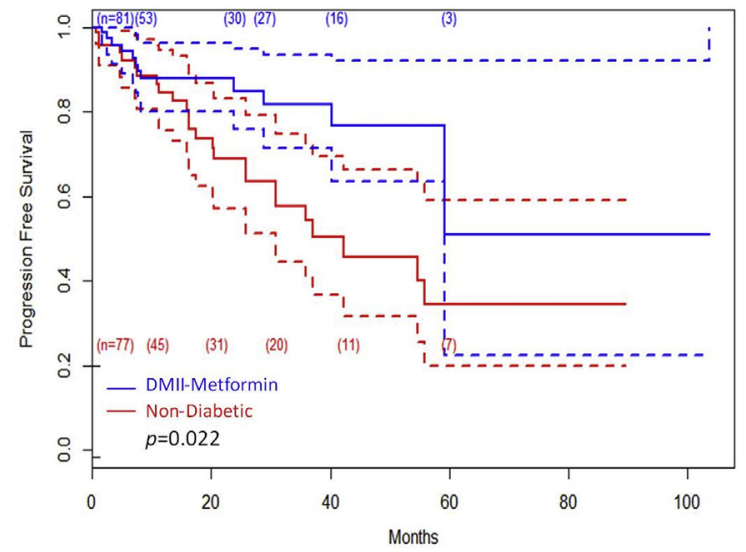

B

FIGURE 2. A, PFS curves, metformin-exposed diabetic versus nonmetformin-exposed diabetic patients (HR, 0.406; 95\% CI, 0.194-0.848; $P=.016)$. B PFS curves, metformin-exposed diabetic versus nondiabetic patients (HR, 0.446; 95\% CI, 0.223-0.891; $P=.022$ ). Solid lines indicate PFS estimates, and dashed lines indicate confidence limits. DM, Diabetes mellitus. 


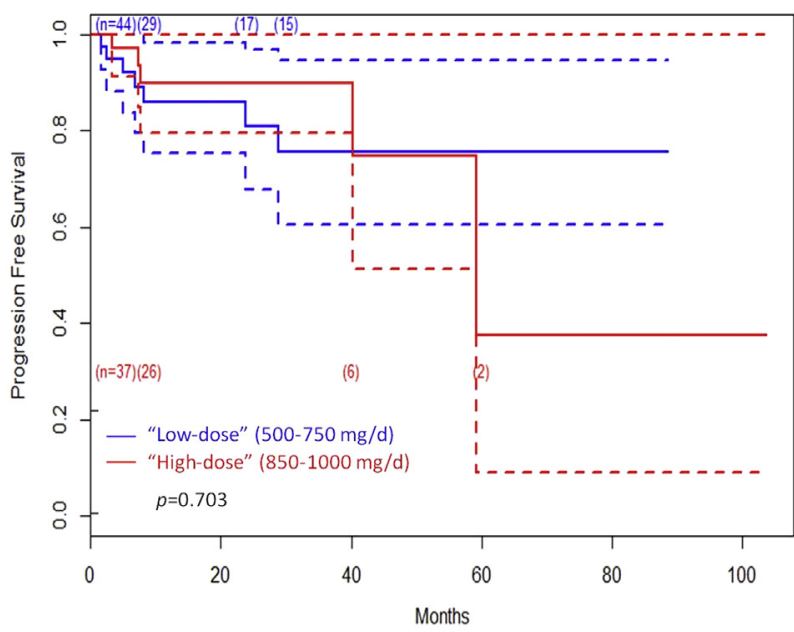

FIGURE 3. PFS curves, low-dose $(500-750 \mathrm{mg} / \mathrm{d})$ versus high-dose (850$1000 \mathrm{mg} / \mathrm{d}$ ) metformin exposure. Solid lines indicate PFS estimates, and dashed lines indicate confidence limits.

metformin monotherapy therapy versus nonmetformin therapy. ${ }^{8}$

Metformin use has been associated with improved PFS and OS compared with insulin use and other oral antidiabetic drugs in patients with advanced NSCLC. ${ }^{9}$ A large population-based study examined the effect of metformin in patients with stage IV NSCLC, showing a significantly longer survival in patients with type 2 diabetes receiving metformin compared with those without metformin treatment. ${ }^{10}$ A recent study also demonstrated improved median PFS and OS among patients with small cell lung cancer treated with metformin. ${ }^{31}$ The current study supports these findings, demonstrating an association between metformin exposure and PFS in those with early-stage lung cancer.

The similar OS with or without metformin exposure may be a reflection of the modest sample size in the current study. However, improved PFS without a difference in OS has been reported with metformin use in ovarian and colorectal cancer. ${ }^{32,33}$ Longer duration of follow-up may be required to demonstrate an association between metformin exposure and OS in early-stage NSCLC.

\section{Study Limitations}

The current study has several limitations. The small sample size and relatively short follow-up duration have the potential to make clinically important differences appear statistically insignificant. Although no difference was reported in pathologic staging between groups, patients in cohort A had higher T- and N-stage tumors than patients in cohorts B and C, potentially introducing bias. However, multivariate and propensity-adjusted analyses demonstrated associations between metformin exposure and PFS. The large number of patients lost to follow-up likely represents the tertiary nature of our medical center; many patients prefer to follow-up with their local oncologist for cancer surveillance. Although this loss to follow-up is a potential confounder, it seems unlikely that those lost to follow-up would preferentially recur. Furthermore, it is plausible that insulin-dependent patients use more health care resources, potentially resulting in more frequent or earlier imaging than noninsulin-dependent patients, confounding the results. However, analysis of their ECOG scores do not reflect a difference in functional status between groups to support this theory. In addition, because of the retrospective nature of the study, the severity of diabetes and effect of chronic hyperglycemia could not be accurately assessed. Although hemoglobin A1C would have been the ideal surrogate for long-term diabetic control, these data were inconsistently documented in the medical record. Likewise, although metformin dosing is reported, the duration of use was not analyzed because of limited

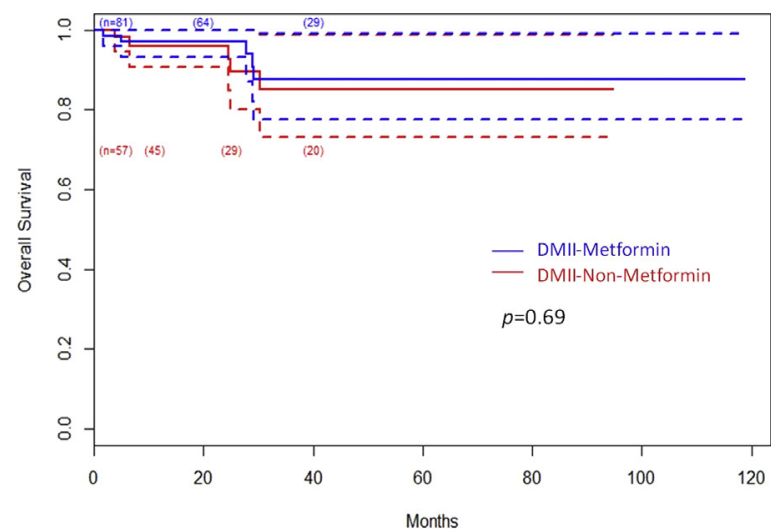

A

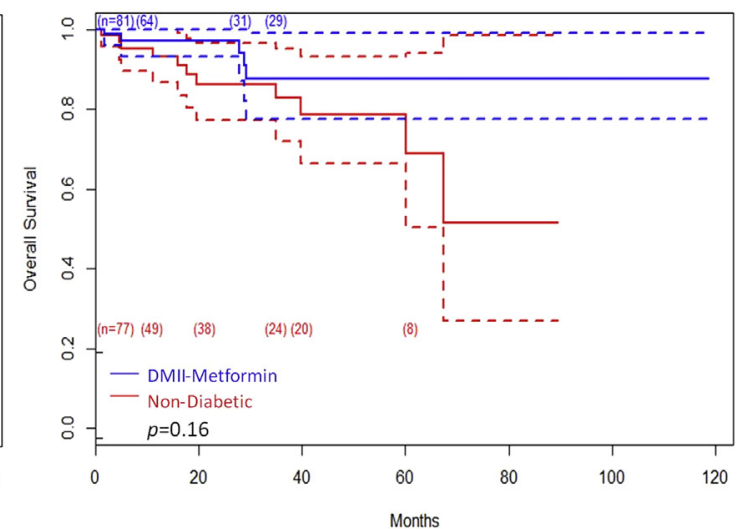

B

FIGURE 4. A, OS curves, metformin-exposed diabetic patients versus non-metformin-exposed diabetic patients (HR, 0.778; 95\% CI, 0.225-2.691; $P=.69$ ). B, OS curves, metformin-exposed diabetic versus nondiabetic individuals (HR, $0.47 ; 95 \%$ CI, 0.163-1.362; $P=.16$ ). Solid lines indicate OS estimates, and dashed lines indicate confidence limits. DM, Diabetes mellitus. 
data availability, despite having the potential to affect the metformin-related tumor response. We acknowledge that our definition of PFS resulted in interval-censored data but was analyzed as usual time-to-event data, which is an additional potential limitation of the analysis. Finally, data on cancer-specific survival were not analyzed, which would give the best assessment of metformin-tumor interaction.

\section{CONCLUSIONS}

These data suggest that metformin exposure in diabetic patients who underwent pulmonary resection for earlystage NSCLC is associated with improved PFS. The difference in OS between groups was not statistically significant but was suggestive of a possible effect worthy of additional study. Conflicting evidence continues to emerge surrounding the antineoplastic effects of metformin. Further prospective studies assessing metformin as an adjuvant agent in lung cancer are needed to determine whether there is a role for metformin in the treatment of early-stage lung cancer.

\section{Conflict of Interest Statement}

Gary Chmielewski, Michael Liptay, and Christopher Seder report consulting fees from Covidien. All other authors have nothing to disclose with regard to commercial support.

\section{References}

1. American Cancer Society (2014). Cancer facts \& figures 2014. Available at: http://www.cancer.org/acs/groups/content/@research/documents/webcontent/ acspc-042151.pdf. Accessed October 6, 2014.

2. Nykamp V. Surgical treatment of non-small cell lung cancer. S D Med. 2010;Spec No:57-9.

3. Noto H, Goto A, Tsujimoto T, Noda M. Cancer risk in diabetic patients treated with metformin: a systematic review and meta-analysis. PLoS One. 2012;7:e33411.

4. Zhang ZJ, Li S. The prognostic value of metformin for cancer patients with concurrent diabetes: a systematic review and meta-analysis. Diabetes Obes Metab. 2014;16:707-10.

5. Zakikhani M, Dowling R, Fantus IG, Sonenberg N, Pollak M. Metformin is an AMP kinase-dependent growth inhibitor for breast cancer cells. Cancer Res. 2006;66:10269-73

6. Liu J, Li M, Song B, Jia C, Zhang L, Bai X, et al. Metformin inhibits renal cell carcinoma in vitro and in vivo xenograft. Urol Oncol. 2013;31:264-70.

7. Storozhuk Y, Hopmans SN, Sanli T, Barron C, Tsiani E, Cutz JC, et al. Metformin inhibits growth and enhances radiation response of non-small cell lung cancer (NSCLC) through ATM and AMPK. Br J Cancer. 2013;108:2021-32.

8. Currie CJ, Poole CD, Jenkins-Jones S, Gale EA, Johnson JA, Morgan CL. Mortality after incident cancer in people with and without type 2 diabetes: impact of metformin on survival. Diabetes Care. 2012;35:299-304.

9. Tan BX, Yao WX, Ge J, Peng XC, Du XB, Zhang R, et al. Prognostic influence of metformin as first-line chemotherapy for advanced non-small cell lung cancer in patients with type 2 diabetes. Cancer. 2011;117:5103-11.

10. Lin JJ, Gallagher EJ, Sigel K, Mhango G, Galsky MD, Smith CB, et al. Survival of stage IV lung cancer patients with diabetes treated with metformin. Am J Respir Crit Care Med. 2015;191:448-54.

11. Leone A, Di Gennaro E, Bruzzese F, Avallone A, Budillon A. New perspective for an old antidiabetic drug: metformin as anticancer agent. Cancer Treat Res. 2014;159:355-76.

12. Goldstraw P, Crowley J, Chansky K, Girous DJ, Groome PA, Rami-Porta R, et al. The IASLC lung cancer staging project: Proposals for the revision of the TNM stage groupings in the forthcoming (seventh) edition of the TNM classification of malignant tumours. J Thorac Oncol. 2007;2:706-14.

13. Groome PA, Bolejack V, Crowley JJ, Kennedy C, Krasnik M, Sobin LH, et al. The IASLC lung cancer staging project: validation of the proposals for revision of the $\mathrm{T}, \mathrm{N}$, and $\mathrm{M}$ descriptors and consequent stage groupings in the forthcoming (seventh) edition of the TNM classification of malignant tumours. J Thorac Oncol. 2007;2:694-705.

14. Oppong BA, Pharmer LA, Oskar S, Eaton A, Stempel M, Patil S, et al. The effect of metformin on breast cancer outcomes in patients with type 2 diabetes. Cancer Med. 2014:3:1025-34.

15. Xie J, Liu C. Adjusted Kaplan-Meier estimator and log-rank test with inverse probability of treatment weighting for survival data. Stat Med. 2005;24 3089-110.

16. Therneau TM, Crowson CS, Atkinson EJ. Adjusted survival curves. Available at: https://cran.r-project.org/web/packages/survival/vignettes/adjcurve.pdf. Accessed October 5, 2015.

17. Austin PC. An introduction to propensity-score methods for reducing the effects of confounding in observational studies. Multivariate Behav Res. 2011;46: 399-424.

18. Franciosi M, Lucisano G, Lapice E, Strippoli GF, Pellegrini F, Nicolucci A. Metformin therapy and risk of cancer in patients with type 2 diabetes: systematic review. PLoS One. 2013;8:e71583.

19. Evans JM, Donnelly LA, Emslie-Smith AM, Alessi DR, Morris AD. Metformin and reduced risk of cancer in diabetic patients. BMJ. 2005;330:1304-5.

20. Decensi A, Puntoni M, Goodwin P, Cazzaniga M, Gennari A, Bonanni B, et al Metformin and cancer risk in diabetic patients: a systematic review and metaanalysis. Cancer Prev Res. 2010;3:1451-61.

21. Sakoda LC, Ferrara A, Achacoso NS, Peng T, Ehrlich SF, Quesenberry CP Jr et al. Metformin use and lung cancer risk in patients with diabetes. Cancer Prev Res (Phila). 2015;8:174-9.

22. Yu H, Yin L, Jiang X, Sun X, Wu J, Tian H, et al. Effect of metformin on cancer risk and treatment outcome of prostate cancer: a meta-analysis of epidemiological observational studies. PLoS One. 2014;9:e116327.

23. Ahmed I, Ferro A, Cohler A, Langenfeld J, Surakanti SG, Aisner J, et al Impact of metformin use on survival in locally-advanced, inoperable non-small cell lung cancer treated with definitive chemoradiation. J Thorac Dis. 2015;7: $346-55$.

24. Shaw RJ, Lamia KA, Vasquez D, Koo SH, Bardeesy N, Depinho RA, et al. The kinase LKB1 mediates glucose homeostasis in liver and therapeutic effects of metformin. Science. 2005;310:1642-6.

25. Kourelis TV, Siegel RD. Metformin and cancer: new applications for an old drug Med Oncol. 2012;29:1314-27.

26. Nieminen AI, Eskelinen VM, Haikala HM, Tervonen TA, Yan Y, Partanen JI, et al. Myc-induced AMPK-phospho p53 pathway activates Bak to sensitize mitochondrial apoptosis. Proc Natl Acad Sci U S A. 2013;110:E1839-48.

27. Kalender A, Selvaraj A, Kim SY, Gulati P, Brûlé S, Viollet B, et al. Metformin, independent of AMPK, inhibits mTORC1 in a rag GTPase-dependent manner Cell Metab. 2010;11:390-401.

28. Quinn BJ, Dallos M, Kitagawa H, Kunnumakkara AB, Memmott RM, Hollander MC, et al. Inhibition of lung tumorigenesis by metformin is associated with decreased plasma IGF-I and diminished receptor tyrosine kinase signaling. Cancer Prev Res. 2013;6:801-10.

29. Landman GW, Kleefstra N, van Hateren KJ, Groenier KH, Grans RO, Bilo HJ. Metformin associated with lower cancer mortality in type 2 diabetes: Zodiac16. Diabetes Care. 2010;33:322-6.

30. Mazzone PJ, Rai H, Beukemann M, Xu M, Jain A, Sasidhar M. The effect of metformin and thiazolidinedione use on lung cancer in diabetics. BMC Cancer. 2012; $12: 410$.

31. Xu T, Liang G, Yang L, Zhang F. Prognosis of small cell lung cancer patients with diabetes treated with metformin. Clin Transl Oncol. 2015;17:819-24.

32. Romero IL, McCormick A, McEwen KA, Park S, Karrison T, Yamada SD, et al. Relationship of type II diabetes and metformin use to ovarian cancer progression, survival, and chemosensitivity. Obstet Gynecol. 2012;119:61-7.

33. Spillane S, Bennett K, Sharp L, Barron TI. Metformin exposure and disseminated disease in patients with colorectal cancer. Cancer Epidemiol. 2014;38:79-84.

Key Words: lung cancer, diabetes, survival, Metformin, outcomes 
TABLE E1. Unweighted and inverse probability-weighted standardized differences for patients with metformin exposure (cohort A) and without metformin exposure (cohort B)

Inverse

Unweighted SD probability-weighted SD

\begin{tabular}{lrr}
\hline Age & 0.146763556 & -0.177048851 \\
Creatinine & 0.739891213 & 0.303401416 \\
FSG & 0.173441594 & 0.047828304 \\
Gender & 0.086124972 & 0.053719813 \\
N1 & 0.320324194 & 0.076358695 \\
T1a & -0.146470441 & 0.002894285 \\
T1b & 0.006853657 & -0.025393409 \\
T2a & 0.074667730 & 0.050060961 \\
T2b & -0.015070858 & -0.018886240 \\
Adenocarcinoma & -0.069010183 & 0.050839344 \\
Squamous cell & 0.339050439 & 0.048520095 \\
Path, other & -0.188186636 & -0.038673132 \\
\hline
\end{tabular}

$S D$, Standardized difference; $F S G$, fasting serum glucose.
TABLE E2. Unweighted and inverse probability-weighted standardized differences for patients with metformin exposure (cohort A) and nondiabetic patients (cohort C)

Inverse

Unweighted SD probability-weighted SD

\begin{tabular}{lrr}
\hline Age & -0.09625344 & 0.108979874 \\
BMI & -0.84320241 & -0.266300683 \\
Gender & -0.05004333 & -0.034413224 \\
N1 & 0.37635496 & 0.108717658 \\
COPD & 0.03048377 & 0.130645450 \\
T1a & -0.29297662 & -0.068507259 \\
T1b & 0.08912843 & 0.094038237 \\
T2a & 0.45910250 & 0.096789232 \\
T2b & -0.15249957 & -0.068341815 \\
ECOG 0 & 0.25724830 & 0.086352262 \\
ECOG 1 & -0.07605304 & -0.054173536 \\
ECOG 2 & -0.20654810 & -0.023982023 \\
Adenocarcinoma & 0.38956518 & 0.156832618 \\
Squamous cell & -0.09344299 & 0.002765884 \\
Path, other & -0.58976782 & -0.410587724
\end{tabular}

$S D$, Standardized difference; $B M I$, body mass index; $C O P D$, chronic obstructive pulmonary disease; $E C O G$, Eastern Cooperative Oncology Group. 